\title{
Changes Needed in Saudi Universities' Mathematics Curricula to Satisfy the Requirements of Vision 2030
}

\author{
Mansour Alabdulaziz ${ }^{1^{*}}$ \\ ${ }^{1}$ Department of Curriculum and Instruction, College of Education, Imam Abdulrahman Bin Faisal University, P.O. Box 2375, \\ Dammam 31451, SAUDI ARABIA
}

Received 21 December 2018 - Revised 10 April 2019 • Accepted 7 May 2019

\begin{abstract}
The aim of this study is to improve the quality of the mathematics curricula in Saudi universities by investigating the required changes in mathematics curricula in order to satisfy the demands of the Saudi Vision 2030. The researcher used qualitative methods to answer the research questions by randomly selecting a sample composed of some faculty members who specialised in curricula and methods of teaching mathematics. In addition, some of undergraduate and postgraduate students. I founded that the current mathematics curriculum in Saudi universities lacks some important requirements and needs to be changed in order to satisfy the demands of Vision by including what is important for the integration of technology into the undergraduate and postgraduate mathematics curriculum. Furthermore, the mathematics laboratory must be an integral part of the curriculum. Moreover, problem-solving ought to be at the centre of a mathematics curriculum. This study concludes with recommendations regarding future research.
\end{abstract}

Keywords: Saudi Arabia's Vision for 2030, development of mathematics curriculums, Saudi universities

\section{INTRODUCTION}

On 25 April 2016, Saudi Arabia introduced the National Transformation Program (NTP) and "Vision 2030". One of the aims of this is that a minimum of five universities in Saudi Arabia be included in the international ranking of the best 200 universities to help students to in attaining which exceed international averages within globally-based education indicators. Its ultimate purpose is to develop an up-to-date curriculum concentrating upon high literacy and numeracy standards as well as character development and abilities. In addition to keeping a record of progress, this will publish a highly-developed scope of educational results which demonstrate annual enhancements (Saudi Arabia's Vision for 2030, 2017). It will consequently supply everyone with exceptional learning opportunities. These will enhance learning results and quality in order to motivate creation and innovation. They will also upgrade the employees' educational abilities and skills as well as developing the curriculum (Saudi Arabia's Vision for 2030, 2017). The principal resource for attaining educational objectives is the curriculum. These objectives include enabling people to obtain qualifications which would be advantageous to themselves. They would also accept responsibility and attain extensive development in their societies which would also benefit (Abdul Salam, 2006).

Also another aim of the Saudi vision is to develop an education system which is able to manage market requirements, thereby constructing a successful economy (Vision, 2030). The way in which education contributes to the Saudi economy needs to be understood (Alzahrani, 2017). We are aware that mathematics forms the basis of science and technology, meaning that the level of economic and social development has a close association with that of the mathematical sciences (Kuku, 2012). Additional, the production of technicians and technologists in any society is dependent upon the level of the study of mathematics in that society. Therefore, it has been claimed that the gap between the standard of teaching and learning mathematics leads to the gap in the development progress between developing nations and advanced nations (Ukeje, 2002).

(C) 2019 by the authors; licensee Modestum Ltd., UK. This article is an open access article distributed under the terms and conditions of the Creative Commons Attribution License (http://creativecommons.org/licenses/by/4.0/). \malabdulaziz@iau.edu.sa (Correspondence) 


\section{Contribution of this paper to the literature}

- Firstly, the current study extended the recommendations of previous studies, such as that of Alabdulaziz (2016) which has made recommendations that further studies be conducted in order to investigate the skills in mathematics provided by universities and colleges for their students. This is to enable them, in the future, to benefit from the technology they learn in schools.

- Secondly, the above studies focused on the science curriculum and English as a foreign language (EFL) teachers; for example, the studies conducted by Alhomairi (2018), Alzahrani and Rajab (2017), and Alzahrani (2017), but the current study focused on the mathematics curriculum. Furthermore, this study adopts the semi-structured interview method, which researchers have not used previously in Saudi Arabia in this context.

- Thirdly, one of these studies consisted of a sample of only teachers in public schools, while another study considered teachers, educational supervisors and stakeholders in public schools in Saudi. Furthermore, in this study the sample consisted of some faculty members specialising in curriculum and methods of teaching mathematics in Saudi universities. Additionally, the study considered some bachelor and postgraduate students.

There is a gap between the skills which students acquire and the current necessities of life and work. These gaps are particularly troublesome when considering the numerous benefits of education in our rapidly-changing global economy. Education ought to be reconstructed in order to satisfy the goals of Vision 2030 (Al-Maimooni, 2016). Therefore, the present study aims to investigate Vision 2030 in Saudi Arabia and the required changes to the mathematics curricula in the universities. In the title of this research, I used the word 'change'. This is because I have investigated some courses in some Saudi universities and to what extent some of their goals and outputs came close to implementing the vision, and I found that their curricula need to change to satisfy the demands of the Vision of Saudi 2030 as shown the table below (some of the courses' names differ from the other universities but they have almost the same goals; therefore, I will not name these courses).

We can see from the table below that the goals of course one does not meet the objectives of the Saudi vision mentioned above, particularly, goals one, two, three, five, six and seven. Additionally, course two does not meet the aims of the vision, particularly goals two, three, four, five, six and seven. Furthermore, course three finds it difficult to fulfil the proposed aims. Moreover, we can see that as per the objectives of course number one, two and three, they cannot meet the aims of the vision, particularly, goals two to seven.

\begin{tabular}{|c|c|c|c|}
\hline The aims of Vision & \multicolumn{3}{|c|}{$\begin{array}{l}\text { 1- Improve the results of quality education. } \\
\text { 2- Provide educational opportunities for everyone in a suitable learning environment. } \\
\text { 3- Increase the efficiency of scientific research. } \\
\text { 4- Enhance the skills and abilities of staff in the field of education. } \\
\text { 5- Motivate innovation and creativity. } \\
\text { 6- Close the gap between the labour market's necessities and the results of higher education. } \\
\text { 7- Assist students in the direction of suitable professional choices. }\end{array}$} \\
\hline Course Title & $\begin{array}{l}\text { 1- Course one } \\
\text { (Postgraduate) }\end{array}$ & 2- Course two (Postgraduate) & $\begin{array}{l}\text { 3- Course three } \\
\text { (Undergraduate) }\end{array}$ \\
\hline $\begin{array}{l}\text { The objectives of the } \\
\text { course }\end{array}$ & $\begin{array}{l}\text { This course aims to help students } \\
\text { to know about a number of } \\
\text { teaching models and advanced } \\
\text { teaching strategies based on } \\
\text { some of the theories and models } \\
\text { of learning. }\end{array}$ & $\begin{array}{l}\text { This course aims to help } \\
\text { students know about the } \\
\text { concept of curriculum } \\
\text { evaluation and its objectives, the } \\
\text { steps and criteria of the } \\
\text { curriculum evaluation and the } \\
\text { aspects of evaluation of the } \\
\text { curriculum and its components, } \\
\text { curriculum evaluation tools. }\end{array}$ & $\begin{array}{l}\text { This course: } \\
\text { 1-Defines mathematics and } \\
\text { explains its structure and evolution } \\
\text { and the difference between } \\
\text { mathematics as a science and as a } \\
\text { subject. } \\
\text { 2- Defines the objectives of } \\
\text { mathematics teaching for primary } \\
\text { classes. } \\
\text { 3- Differentiates between learning } \\
\text { and teaching standards in primary } \\
\text { grades. } \\
4-\text { Compares different learning } \\
\text { aspects of mathematics (concepts, } \\
\text { skills and generalisations). }\end{array}$ \\
\hline
\end{tabular}

\section{Statement of the Problem}

There is certainly a gap between the current requirements of life and work and the mathematical skills which students obtain. We may indeed assert that, in both of these areas, students have been insufficiently prepared by 
the curriculum. In fact, the inadequacy of the results of learning from the current science projects in preparing students for life and work has been discovered by Bybee (2010). Since students are being prepared for various employment types, they are likely to encounter a crisis since these employment types will disappear if they have not so already done so. It has been verified by research that the at an international level as well as at an Arabic one it is obviously inadequate in preparing students for twenty-first century life and work (Shalabi, 2014). Therefore, the aim of this study is to improve the quality of mathematics curricula in Saudi universities by investigating the required changes in them in order to satisfy the demands of Vision 2030.

\section{Importance of the Study}

The aims of Vision 2030 in Saudi Arabia were mentioned in the introduction above; consequently, as we are aware of mathematics being at the basis of both science and technology, the standard of economic and social advance has a close association with the developmental level in mathematical sciences (Kuku, 2012). Affirmation has emerged that the cause of the gap in the developmental level between developing and advanced nations is the gap in the standard of teaching and learning in mathematics (Ukeje, 2002). There is a gap between the skills which students acquire and the current necessities of life and work. Education ought to be reconstructed in order to satisfy the goals of Vision 2030 (Al-Maimooni, 2016). Therefore, the present study aims to investigate Vision 2030 in Saudi Arabia and the required changes to the mathematics curricula in universities.

\section{The Research Boundaries}

These can be summarised as follows:

1- This study focused only on mathematics curricula in Saudi universities.

2- The study sample focused on faculty members, undergraduate and postgraduate students.

\section{Research Question}

The present study aims to provide answers for these two main questions:

1- What is the effective mathematics curriculum that needs to be adopted to satisfy the demands of the Saudi Arabia Vision 2030?

2- Does the current mathematics curriculum for undergraduates and postgraduates adequately prepare students for the workplace?

\section{LITERATURE REVIEW}

\section{Theoretical Framework}

I did, in fact, give consideration to the Tyler's model. However, I decided not to use it since I am of the opinion that the Tyler's model sees curriculum development as a fixed, linear process. Instead of a linear model, Wheeler developed a cyclical model. Therefore, Wheeler's model for curriculum design is an improvement upon Tyler's model. It goes on as the needs and interests of society change and the objectives also change.

The theoretical frameworks adopted to undertake this research include the Wheeler model of curriculum development (1967), or cyclic model, asserts that curriculum is a continuous cycle responding to the changes within education and makes appropriate adjustments to account for these changes. This model is consisted of five logically sequenced phases, those being: Selecting aims, goals and objectives, selecting learning experiences, selecting the content, integrating and organising learning experiences and content, and evaluating.

\section{The Saudi Vision 2030}

Saudi Arabia's Vision 2030 project was launched by Prince Mohammed bin Salman Al Saud, crown prince, who is chairman of the Council of Economic and Development Affairs, on 25 April. This extensive programme will guide the nation towards economic diversification. The Vision involves the following three basic targets: a strong economy, a dynamic society and an enterprising country. Although the principal focus of Vision 2030 is in the direction of several business investment enterprises, cultural programmes and economic reforms, it is impossible to introduce such programmes without there being quality education. Since the dependence of Saudi Arabia on oil revenues is decreasing, it is necessary to transform the nation's economy, for which the Saudi Government has prepared a number of courses of action. HRH Prince Mohammed bin Salman declared that Vision 2030 is one principal measure which led to a major economic change subsequent to the inception of the country in 1932 (Yusuf \& Atassi, 2016). 
It has been revealed recently by the World Index of Education that the Kingdom of Saudi Arabia ranks in $34^{\text {th }}$ place out of 187 nations across the world. This index, which was 0.3 in 1980, gradually increased until it attained the figure of 0.7 by 2017, which indeed forecasts that in future years the nation will have an even more advanced ranking. Moreover, the Kingdom of Saudi Arabia is of the opinion that education is the means by which countries can progress and develop. However, nations which have disregarded education continue to have lower rankings. Consequently, since Saudi Arabia appreciates the significant function of education, the country has recently employed a method of proceeding by declaring Vision 2030 as attaining the following targets: improve the results of quality education; provide educational opportunities for everyone in a suitable learning environment; formulate community partnership; increase the efficiency of scientific research; enhance the skills and abilities of staff in the field of education; motivate innovation and creativity; close the gap between the labour market's necessities and the results of higher education; and advance public education and assist students in the direction of suitable professional choices. It also involves supplying them with opportunities of rehabilitation as well as mobility and adaptability between various educational options (Saudi Arabia's Vision for 2030, 2017).

\section{Previous Research and Studies}

Starting with (Alhomairi, 2018), his study was aimed at attaining agreement among a group of educational experts regarding the significance of supplying a science curriculum appropriate for primary grades five and six which assists in the attainments needed for the development of the 2030 Kingdom's Vision. Furthermore, its intention was to consider the educational experts' perceptions regarding the advancement of the science curriculum in order to have an improved way of attaining this vision. The Delphi technique and the descriptive method were utilised in this study which was used with a group of 28 educational experts within three sessions, between 8 October, and 9 November 9, 2017. The weakness of the provision degree of the needs of Vision 2030 in the advancement of the science curriculum was discovered by the results. With regard to the development of the science curriculum in attaining the vision's requirements, the educational experts' responses at the conclusion of the third session were in the range of "agree" and "strongly agree". Finally, a perspective for advancing the science curriculum was advocated according to the opinions of the experts participating in the current study.

In their study, Alzahrani and Rajab (2017) sought to investigate the perceptions and opinions of English as a Foreign Language (EFL) teachers in public schools in Saudi Arabia in order to attain the Kingdom's 2030 Vision. This is associated with the educational development generally and with the EFL discipline specifically. In order to apply the descriptive method, the study used a survey tool comprising 19 items split into four constructs. The study sample comprised 450 males and 550 females in Saudi Government schools involving teachers of EFL from the principal areas of the nation. The participants' responses, when statistically analysed, revealed results that showed an exceptionally high degree of positive opinion regarding professional development in English Language (EL) teaching. This attained 91 percent in addition to almost unanimous participants' responses. This was portrayed in the shortage of any statistically important association between participants responses towards regarding the 2030 Vision by attaining professional development. It also sought to formulate a network of English teachers across the world. Additionally, the outcomes revealed that some hindrances exist which could have a negative impact upon implementing Vision 2030 in the Kingdom of Saudi Arabia. Consequently, many recommendations have been advocated by the researchers which include undertaking further research to investigate matters not included in this study. Furthermore, it was suggested that further interviews be conducted with a random selection of English teachers in government schools in the nation. The purpose of this is to obtain qualitative outcomes and analyses in assisting the researcher to obtain a wider viewpoint for teachers of the English language in Saudi Arabian public schools. In order to include both female and male students in Saudi Arabian public schools and also English language supervisors and administrators, they added different samples for the purpose of conducting further extensive analyses and to draw further conclusions other than those offered in this study.

Another study, conducted by Alzahrani (2017), provided an overview of the English language potential in contributing to Saudi Vision 2030's success. We intend to achieve this by demonstrating the considerable involvement of the language in the development of technology as well as in the cultural resources of the country, and also in the preparation of highly-skilled labour for the market. Furthermore, the researcher addresses the existing language education practices and policies in the Kingdom as well as their contribution to the economy. According to the results, it is advocated that the Saudi education system is expected to require change for the purpose of managing changes in the market. This is to enable educational policymakers to act in order to include the English language in Vision 2030. The Kingdom of Saudi Arabia will be assisted in attaining the success which is advocated by Vision 2030 by being aware of how language has been utilised by other nations to obtain an influential position within new markets, thereby encouraging the advancement of a knowledge-based economy.

As aforementioned in the introduction, we are aware that mathematics stands at the core of science and technology, meaning that the standard of economic and social advancement has a close association with the developmental standard in the mathematical sciences (Kuku, 2012). Therefore, in the next section, I want to 
demonstrate some studies to the reader which concern the effect of technology on mathematics learning and the relationship between technology and mathematics education.

\section{Technology and Mathematics}

Preparing the teachers of tomorrow to utilise technology is a major issue which is encountered by current teacher education programmes (Kaput 1992; Waits \& Demana 2000). Every facet of mathematical education is affected by the integrated and suitable utilisation of technology. This includes the mathematics which is taught as well as how it is taught, learned and evaluated (National Council of Teachers of Mathematics [NCTM] 2000). For a considerable length of time, changes in the mathematics curriculum have been suggested. This includes the application of technology. According to the National Research Council and the Mathematical Sciences Education Board (MSEB)," the changes in mathematics brought about by computers and calculators are so profound as to require readjustment in the balance and approach to virtually every topic in school mathematics" (MSEB $1990 \mathrm{p}$. 2). Teachers of mathematics will, in the future, be required to be well acquainted with technological matters and applications. If we are to comprehend the association between technology and mathematics, it is necessary that we demonstrate to the reader certain studies regarding the impact of technology upon the learning of mathematics.

Several research studies have concluded that, by utilising means of technology strategically, acquisition of mathematical processes and abilities can be facilitated, and advanced mathematical competences, including problem solving, reasoning, and validating, can be developed (e.g., Gadanidis \& Geiger, 2010; Nelson, Christopher, \& Mims, 2009; Pierce \& Stacey, 2010; Suh \& Moyer, 2007). It is also an important that we demonstrate to the reader a study regarding the barriers to adopting and using technology for teaching and learning mathematics.

Alabdulaziz and Higgins (2016) investigated the barriers that teachers face when using technology in their classroom, and why some overcame obstacles while others did not. Semi-structured interviews and observations were used for the purpose of this research. The researchers found from the interviews' responses and the consequent observations, that the head teacher's support was the main reason behind the decision to overcome or not overcome the obstacles they face when using technology to help students with difficulties in mathematics. The principals of both schools played a crucial role in managing the challenges they faced with technology. In spite of teachers' beliefs that the technology has a positive impact on teaching and in the learning of students who have difficulties in mathematics. The study has made recommendations, which include the need to conduct further studies to investigate the skills provided by universities and colleges for their students in mathematics to allow them to benefit from the technology through their teaching in the schools in the future.

\section{The Mathematics Laboratory}

It was asserted by Okereke (2006) that mathematics lies at the base of science and technology and that its functional application in science and technology is both multifarious and multifaceted. Consequently, the application of mathematics cannot be avoided in any area of business endeavour, technology or science. Furthermore, it was previously advocated by Srinivasa (1978) that the teaching of mathematics ought to involve a mathematics laboratory since this will enable students to form ideas from experiences of discrete objects. When this method is applied, imaginary objects and vague theories assume an authentic shape, allowing the students to obtain a better understanding and improve their performance. Consequently, it is vital to contemplate strategies which may be of assistance to students in enhancing their performance with regard to the impact upon teaching and learning mathematics. According to Okigbo and Osuafor (2008), the utilisation of a mathematics laboratory is of assistance in assimilating theory with practical application in the teaching and learning of mathematics.

\section{Problem Solving in Mathematics Curriculum}

It is accepted that problem solving is a significant life skill which involves many procedures inclusive of: forecasting, analysis, reasoning, interpretation, assessment and reflection. In several nations, this is either a basic component or a comprehensive target of the school mathematics curriculum (Anderson, 2009). Nevertheless, the discovery of methods of resolving problems is a complicated assignment which needs a broad scope of dispositions and skills (Stacey, 2005). In order to resolve non-routine difficulties, it is necessary for students to have profound mathematical knowledge in addition to investigative strategies and the ability to reason. Furthermore, they require personal characteristics and helpful opinions in order to plan and direct their endeavours.

The present study, in fact, differs from the previous ones in the following ways. Firstly, the current study extended the recommendations of previous studies, such as that of Alabdulaziz (2016) which has made recommendations that further studies be conducted in order to investigate the skills in mathematics provided by universities and colleges for their students. This is to enable them, in the future, to benefit from the technology they learn in schools. Secondly, the above studies focused on the science curriculum and English as a foreign language 
(EFL) teachers; for example, the studies conducted by Alhomairi (2018), Alzahrani and Rajab (2017), and Alzahrani (2017), but the current study focused on the mathematics curriculum (I did not find studies focus on mathematics curriculum with vision 2030 in Arab countries, some papers have provided developing mathematics curriculum, but have not linked mathematics curriculum to any developmental plans as did the Kingdom's Vision for 2030. Therefore, the present study is the first to do so). Furthermore, this study adopts the semi-structured interview method, which researchers have not used previously in Saudi Arabia in this context. Thirdly, one of these studies consisted of a sample of only teachers in public schools, while another study considered teachers, educational supervisors and stakeholders in public schools in Saudi.

\section{METHODOLOGY}

The researcher used qualitative methods to answer the research questions. Maxwell (2005) contends that the design of a qualitative study ought to enable it to adapt to the conditions whereby the study is being undertaken. The design ought not to be simply a fixed determining aspect of research practice. This has helped me to answer my research questions according to their views and not according to my own, which gave me different and diverse answers. The sample was selected randomly and consisted of 35 faculty members whose specialities rangied from curriculum and methods of teaching mathematics. These 35 faculty members have various academic backgrounds. Some have between three to ten years' teaching experience and others between 11 and 25 years. Furthermore, 400 undergraduate students and (100 postgraduate students who specialised in curricula and methods of teaching mathematics). Coming back to the literature review, the present study, in fact, also differs from the previous studies as follows. Firstly, in this study the sample consisted of some faculty members specialising in curriculum and methods of teaching mathematics in Saudi universities. Secondly, the study considered some bachelor and postgraduate students specialising in curriculum and methods of teaching mathematics.

Thematic analysis as one of the tools of grounded theory was utilised by the researcher in order to analyse the data. Initially, every interview was recorded and subsequently transcribed and the data were read and re-read. The next stage was the application of thematic coding (underlining the text in various colours) and then the data were matched into separate categories, thereby enabling reduction and synthesis of large amounts of data. Subsequent to this, every recognised commonality was split into topics. It was necessary for the researcher to supply the following three categories of the most significant moral matters. The first category involved the researcher in giving the participant comprehensive details regarding the reason for the research. In the second category the researcher guaranteed the confidentiality of participants' identity and personal details; and therefore, their names would not be included in the course of the translation procedure. The third category involved the researcher clarifying that all participants volunteered to be involved in this programme and had the right to remove any responses which they had been given previously. In the next two sections I will provide some background for this study. It includes a general overview of the Kingdom of Saudi Arabia; this section describes the site of current study. This is followed by the current status of higher education in Saudi Arabia.

\section{General Information of Saudi Arabia}

The Saudi Arabian Kingdom is located at the most distant area of the south west of the Asian continent. Qatar and the United Arab Emirates, which are bordered by the Arabian Gulf are on its eastern border, whereas Jordan, Iraq and Kuwait lie on its northern border. On the west, it borders the Red Sea with Oman and Yemen being on its southern border. Saudi Arabia consists of the following four regions: Central, Western, Southern and Eastern. The Central Region is at the heart of the Kingdom and comprises high country while the Western Region is located on the coast of the Red Sea. The Southern Region is located on the Yemen-Red Sea border district while the stormy and sandy area of the nation comprises the Eastern Region.

\section{The Current Status of Higher Education in Saudi Arabia}

In the Kingdom of Saudi Arabia, both private and public universities are the principal providers of higher education. This includes the Technical and Vocational Training Corporation and other similar higher-education establishments. Public universities are government-funded establishments where it is usual to provide education free of charge, whereas private colleges and universities could provide opportunities for students who were unable to find a place in public universities or for those unable to find an appropriate course, and also for foreign students (Aldiab Chowdhury Kootsookos, \& Alam, 2016). In Saudi Arabia, as indicated by the National Commission for Academic Accreditation and Assessment (2015), qualifications can be categorised into the following seven stages: (1) Entry - Completion of secondary education; (2) Level 1 - Associate Diploma; (3) Level 2 - Diploma; (4) Level 3 Bachelor's Degree; (5) Level 4 - Higher Diploma; (6) Level 5 - Master's Degree; (7) Level 6 - Doctorate. Many courses are offered by the majority of establishments. These include mathematics, chemistry and physics as well as several specialist courses like medical science and engineering. The 29 universities in Saudi Arabia consist of a total of 133 
campuses, the number of which was calculated by counting one campus for each city. However, for some universities, there is more than one campus in the same city; in fact, there are 10 private universities within six different provinces. Furthermore, we can separate public colleges into the following four principal categories: (a) The Technical and Vocational Training Corporation comprising over 56 colleges, (b) The Royal Commission for Jubail and Yanbu comprising five colleges, (c) the Institute of Public Administration (IPA) comprising four campuses and Prince Sultan Military College of Health Sciences, Dhahran as a specialised college. There are also 20 private colleges, the majority of which supply specialist courses in the higher education domain.

\section{RESULTS AND DISCUSSION}

\section{Discussion of the Result by Dimensions}

I will discuss the findings concluded from answers to the interview questions and the literature review according to three aspects: (A) Integration of technology into the undergraduate and postgraduate mathematics curriculum; (B) The mathematics laboratory must be an integral part of mathematics curriculum; (C) Problem solving in the mathematics curriculum.

\section{(A) Integration of technology into the undergraduate and postgraduate mathematics curriculum}

Our opinion in why technology is significant in teaching mathematics is important. We need to consider if it is because we need to prepare students for careers which rely on technology. We also need to consider if it is because today students spend many hours in front of devices. Indeed, I tried to ask these questions to every participant in order to obtain clear answers regarding mathematics and technology and how it relates to Vision 2030.

It is not surprising to discover that all participants, including faculty and students, agree that technology is important in the teaching of mathematics and how it is relevant to the demands of the Saudi Vision 2030. This is because many studies discovered the positive effects of using technology in mathematics teaching and learning. For example, Gadanidis \& Geiger, 2010; Nelson, Christopher, \& Mims, 2009; Pierce \& Stacey, 2010; Suh \& Moyer, 2007).

The participants wished to convey the idea that technology, when integrated into a mathematics curriculum in Saudi universities revolutionises the learning process. Students are engaged in their learning by using these tools and can become creators and critics rather than simply consumers which is what we need in Saudi Vision 2030. Furthermore, we should not forget that technology needs to be an integral part of the current curriculum in each lesson. Furthermore, we should keep in mind that we need to integrate technology and use it appropriately in mathematics education. This is because it has an impact upon every aspect of mathematics education, such as mathematics topics, teaching technique and the method of assessing students.

Furthermore, these findings appear to concur with Kaput (1992) and Waits and Demana (2000) who emphasise that training the teachers of the future in the applications of technology is a significant matter which is encountered by current teacher education projects (Kaput 1992; Waits \& Demana 2000). Every element of mathematical education is affected by the assimilated and suitable utilisation of technology. This is inclusive of the content of mathematics teaching as well as how the subject is taught, learned and evaluated (National Council of Teachers of Mathematics [NCTM], 2000). For a considerable length of time, it has been suggested that the mathematics curriculum should be changed, and this includes the application of technology. It is asserted by the National Research Council and the Mathematical Sciences Education Board (MSEB) that "the changes in mathematics brought about by computers and calculators are so profound as to require readjustment in the balance and approach to virtually every topic in school mathematics" (MSEB 1990 p. 2).

I agree with those participants concerning the importance of technology in teaching mathematics and how it relates to satisfying the demands of the Saudi Vision 2030. Therefore, I think it is important that the faculty and department answer the following questions to enable technology to be of great benefit in teaching mathematics. Which type of technology will be used? What access to the technology do we require or expect of students? In order to achieve the Saudi Vision 2030, we need the students to become creators and critics instead of just consumers.

\section{(B) The mathematics laboratory must be an integral part of mathematics curriculum}

It is true that 99 percent of participants, ranging from faculty members to undergraduate and postgraduate students (master) agreed that the mathematics laboratory should be an integral part of the mathematics curriculum. They mentioned that when mathematical knowledge cannot be translated into practice it is a useless burden, because we need to give the students the opportunity of integrating theory with practice, which will help them to apply mathematical facts and principles in their life in a practical way, which is one of the goals of Saudi Vision 
2030. Indeed, these findings appear to concur with Okigbo and Osuafor (2008), who mentioned that the utilisation of a mathematics laboratory is of assistance in assimilating theory and practical applications in the teaching and learning mathematics.

It is true that 95 percent out of 99 percent of the faculty members that participated above added that mathematics is the foundation of other subjects such as science, technology and business; therefore, none of these subjects can escape from its application. This means the stakeholder ought to take an opportunity to consider the mathematics curriculum and to link it with the mathematics laboratory. This will help students to improve their performance in mathematics. Consequently, mathematics will make it easier for students to learn other subjects without complexity. This is, in fact, consistent with Okereke (2006) who asserted that mathematics lies at the base of science and technology and that its functional application in science and technology is both multifarious and multifaceted. Consequently, the application of mathematics cannot be avoided in any area of business endeavour, technology or science. Furthermore, it was previously advocated by Srinivasa (1978) that the teaching of mathematics ought to involve a mathematics laboratory since this will enable students to form ideas from experiences of discrete objects. When this method is applied, imaginary objects and vague theories assume an authentic shape which allows the students to obtain a better understanding and to improve their performance. Consequently, it is vital to contemplate strategies which may be of assistance to students in enhancing their performance with regard to the impact upon teaching and learning mathematics.

Indeed, we know that Vision 2030's strategic objectives are to focus on the following three principles: achieving governmental operational excellence, improving economic enablers and enhancing the standards of living. Therefore, I agree with those participants that the mathematics laboratory must be an integral part of the mathematics curriculum. In order to satisfy the demands of Saudi Vision 2030, students need to understand mathematics very well so they can facilitate the understanding of other subjects. In other words, mathematics is used in almost every field of human endeavour, be it science, engineering, art or economics. For instance, algebra may be applied to computer sciences, networking, cryptology, and study of symmetry in physics and chemistry. Calculus (differential equations) may be applied to biology, engineering, physics, molecular structure, rocket science, the motion of water as well as option price modelling in economics and business paradigms (Gouba, 2008). Therefore, faculty members who specialise in curricula and methods of teaching mathematics in Saudi universities should ensure that they redesign mathematics curricula in order to help students to understand mathematics clearly and lead them not to stumble in other areas.

One of these aids is the mathematics laboratory which must be an integral part of the mathematics curriculum because we know that some university students may view mathematics as being boring or difficult. Furthermore, when they do not give a direct answer to a mathematical question, they will think that they do not have the ability to study mathematics and will lose interest in learning. Therefore, as faculty members, we need to be enthusiastic in establishing a mathematics laboratory in each university in order to help us to teach mathematics in a differently through puzzles, teaching aids and other materials for conducting activities.

I certainly remember that when I studied for a bachelor's degree and my subject was mathematics, the university gave me just one course named mathematics laboratory one. However, the course was in the regular lecture room and not in a special mathematics laboratory although the students wished to have a special mathematics laboratory. Furthermore, they asked the doctor at that time to provide another course; for example, one named mathematics laboratory two, in fact, they needed not just two but three and four. This was because they had experienced the importance of this course, as they benefitted from it when they were trained in schools. This training was usually conducted during the last term at university.

It is worthy of mention, that four years after receiving my bachelor's degree, I met one of my friends who was studying with me. Firstly, I asked him about himself, about how he felt about matters subsequent to his life at university, and we then discussed our subject, mathematics. Later, he told me that he wished he was still at the university to study mathematics laboratory two, three and four because he felt that the mathematics laboratory course was the only course that contributed greatly to the learning of mathematical concepts and skills. Therefore, I think that if the mathematics laboratory was an integral part of the mathematics curriculum, this would be of considerable help to students regarding the improvement of their understanding of mathematics which is what we require to satisfy the demands of the Saudi Vision.

\section{(C) Problem-solving in the mathematics curriculum}

It has certainly been agreed by 97 percent of the participants from faculty members, 99 percent of undergraduate students and 98 percent of postgraduate students that we need to place problem-solving at the heart of a mathematics curriculum. This would give students a flavour, according to their capabilities, of what it is to be a mathematician; and a taste for rising to a mathematical challenge and overcoming it. 
As many as 97 percent of the aforementioned faculty member participants think that the mathematics curriculum should equip students to solve problems. If we ask ourselves why we need problem-solving in the mathematics curriculum, they believe that it contributes to the generic skill of problem-solving in daily life. We need to improve students' performance in solving problems correctly through the mathematics curriculum, and because this tool solves problems, we need it in the Saudi Vision 2030. Therefore, when we place problem-solving at the heart of a mathematics curriculum, this will enable us to help students to be aware of the problem-solving strategies. Furthermore, this will help students to improve their willingness to tackle problems and they will be excited if they solve any problem. Moreover, we will see that the students have the ability to implement solution strategies in a systematic manner.

As many as 90 percent of the undergraduate student participants mentioned that they would like to be aware of this problem-solving approach because they will need it in their lives in the future. Furthermore, 10 percent of them mentioned that problem-solving in the mathematics curriculum would help them to apply analysis, interpretation and evaluation. However, 2 percent of them stated that they would also help them to make decisions when they face any problem in mathematics or in life generally. Moreover, they think they could not make a decision if the topic of problem-solving was not in the mathematics curriculum. It is accepted that the resolution of problems is a significant life skill which involves many procedures inclusive of: forecasting, analysis, reasoning, interpretation, assessment and reflection. In several nations, this is either a basic component or a comprehensive target of the school mathematics curriculum (Anderson 2009). Nevertheless, the discovery of methods of resolving problems is a complicated assignment which needs a broad scope of dispositions and abilities (Stacey 2005). In order to resolve non-routine difficulties, it is necessary for students to have profound mathematical knowledge in addition to investigative strategies and the ability to reason. Furthermore, they require personal characteristics and helpful opinions in order to plan and direct their endeavours.

As many as 89 percent of undergraduate student participants and 98 percent of postgraduate students mentioned that some friends are currently training in schools. This is usually because in the final term, the university's students are required to visit a school, bringing with them a letter from the university which allows them to practise teaching just for one term. At the end of the term, the student's supervisor and the school principal will usually assess the students. In fact, the participants told me that those friends faced problems during their teaching, one such problem being that they found it difficult to make decisions when encountering a problem with students, the curriculum and with teaching methods. Furthermore, it was usual for them to say that they did not learn how to solve those problems when they were studying in university.

I certainly agree with those participants that we need to place problem-solving at the heart of a mathematics curriculum because the whole purpose of learning mathematics is to be able to solve problems. I remember when I asked my students in university why they are learning mathematics, I felt that their answers were depressing because the most frequent answers included that learning of mathematics is like passing tests or generally learning rules and facts.

I think that mathematics provides the solution to some of life's problems. Problem-solving is essential to everyday life, critical to science, technology and engineering, and necessary for financial literacy and most forms of employment. Therefore, we need a strong curriculum help us to solve problems. I think problem-solving in mathematics not only concerns students memorising procedures but also searching for solutions, and not only students conducting exercises but also formulating conjectures.

When moving to the second research question which asks if the current undergraduate mathematics curriculum adequately prepares students for the workplace, it is not surprising to find that all participants, including faculty and students, agree that the current undergraduate mathematics curriculum does not adequately prepare students for the workplace. This is because they think that the current mathematics curriculum in Saudi universities lacks a set of important requirements and needs to be changed in order to satisfy the demands of the Vision. This is ranked according to priority and importance. Firstly, it is important to integrate technology into the undergraduate and postgraduate mathematics curriculum. Secondly, the mathematics laboratory must be an integral part of the mathematics curriculum. Thirdly, problem-solving needs to be placed at the heart of a mathematics curriculum.

Coming back to the theoretical framework that adopted to undertake this research (the Wheeler model of curriculum development) (1967), asserts that curriculum should be a continuous cycle which is responsive to changes in the education sector and makes appropriate adjustments to account for these changes. This consistent with all the objectives of the new vision, because we need to lower the gap between the skills which students acquire and the current necessities of life and work. These gaps are particularly troublesome when considering the numerous benefits of education in our rapidly-changing global economy.

I think that there is relationship between mathematics education and national prosperity. Vision 2030 calls people to build a strong economy which will happen by leveraging a broad range of talents, skills and competences. This means that universities need to build an education system which prepares highly-skilled graduates. However, 
I think that we need students and faculty members to contribute to the necessary change in order to help the new students to have skills and knowledge for successful application and practice.

\section{RECOMMENDATIONS}

I recommend that stakeholders in Saudi take advantage of the answers which were presented by the participants to satisfy the demands of Vision 2030. In addition, further studies need to be conducted to compare vision 2030 of Saudi Universities mathematics curriculum with other countries. Furthermore, this study could be replicated and extended to include primary, middle and high schools. Moreover, this study focused on the mathematics curriculum, but another study could focus on other areas of the education field.

\section{CONCLUSION}

The aim of this study is to improve the quality of the mathematics curriculum in Saudi universities by investigating the required changes in universities' mathematics curricula in order to satisfy the demands of the Vision of Saudi 2030. I found that current mathematics curricula in Saudi universities lacks a set of important requirements and need to be changed in order to satisfy the demands of Vision 2030. The includes the importance of integrating technology into the undergraduate and postgraduate mathematics curricula. Furthermore, the mathematics laboratory must be an integral part of the curriculum. Moreover, problem-solving needs to be at the heart of a mathematics curriculum.

\section{ACKNOWLEDGEMENT}

I would like to thank our almighty God who gave me the power and the will to finish this research. I would like to extend my warmest thanks to all the participants in the research for making their time available for sharing of information.

\section{REFERENCES}

Abdul Salam, M. A. (2006). Developing the Educational Curriculum to Fulfill the Requirements of Development and Meet the Challenges of Globalization. A Research Presented to the Conference of Qualitative Education and its Role in Human Development in the Era of Globalization, the 1st Scientific Conference of the Faculty of Special Education, Mansoura University on April, 12-13, 271-310.

Alabdulaziz, M., \& Higgins, S. (2016). Obstacles to Technology use When Addressing Saudi Primary Students' Mathematics Difficulties. International Journal of Engineering Research \& Technology (IJERT), 5(10), $412-417$. Retrieved from http:/ / www.ijert.org

Aldiab, A., Chowdhury, H., Kootsookos, A., \& Alam, F. (2017). Prospect of eLearning in Higher Education Sectors of Saudi Arabia: A Review. Energy Procedia, 110, 574-580. https://doi.org/10.1016/j.egypro.2017.03.187

Alhomairi, A. O. (2018). A Proposed Perspective for Developing Science Curriculum for the Upper Primary Grades in accordance to Saudi Arabia's Vision for 2030: An Analytical and Descriptive Study according to Delphi Method. International Journal of Higher Education, 7(1), 96- 86. https:/ / doi.org/10.5430/ijhe.v7n1p69

Al-Maimooni, M. (2016). A one trillion riyal non-oil revenue approaching: Deputy crown prince reveals 13 national initiatives for Kingdom's future Vision 2030. Al-Yaum Newspaper. Retrieved from http:/ / www.alyaum.com/article/4133366

Alzahrani, A. K. (2017). Markets and language policy in Saudi Arabia: how the English language can contribute to the success of the Saudi vision 2030. International Journal of English Language and Linguistics Research, 5(6), 112. Retrieved from https://www.eajournals.org

Al-Zahrani, N. O. A., \& Rajab, H. (2017). Attitudes and Perceptions of Saudi EFL Teachers in Implementing Kingdom of Saudi Arabia's Vision 2030. International Journal of English Language Education, 5(1), 83-99. Retrieved from https:/ / doi.org/10.5296/ijele.v5i1.10733

Alzahrani, N., \& Rajab, H. (2017). Attitudes and Perceptions of Saudi EFL Teachers in Implementing Kingdom of Saudi Arabia's Vision 2030. International Journal of English Language Education, 5(1), 83-99. https:// doi.org/10.5296/ijele.v5i1.10733

Anderson, J. (2009). Mathematics Curriculum Development and the Role of Problem Solving. ACSA Conference 2009. Retrieved from https https://www.researchgate.net/publication/255630930_Mathematics_Curriculum_ Development_and_the_Role_of_Problem_Solving 
Bybee, R. W. (2010). The Teaching of Science 21st Century Perspectives, National Science Teachers Associations. Arlington: NSTA Press.

Gadanidis, G., \& Geiger, V. (2010). A social perspective on technology enhanced mathematical learning - from collaboration to performance. ZDM, 42(1), 91-104. https:/ / doi.org/10.1007/s11858-009-0213-5

Kaput, J. J. (1992). Technology and mathematics education. In D. A. Grouws (Ed.), Handbook of research on mathematics teaching and learning, (pp. 515-556). New York: MacMillan Publishing Company.

$\mathrm{Kuku}$, A. O. (2012). Mathematics as a time-tested resource for scientific, technological, socioeconomic and intellectual development. Distinguished Mathematics Lecture delivered at the University of Ibadan. Ibadan: Ibadan University Press

Mathematical Sciences Education Board. (1990). Reshaping school mathematics: A philosophy and framework for curriculum. Washington, DC: National Academy Press.

National Commission for Academic Accreditation \& Assessment. (2015). National Qualifications Framework for Higher Education in the Kingdom of Saudi Arabia.

National Council of Teachers of Mathematics. (2000). Principles and standards for school mathematics. Reston, VA: Author.

Nelson, J., Christopher, A., \& Mims, C. (2009). TPACK and web 2.0: Transformation of teaching and learning. Tech Trends, 53(5), 80-85. https:// doi.org/10.1007/s11528-009-0329-z

Okereke, S. C. (2006). Effects of prior knowledge of implications of mathematical tasks /concepts to career types and gender on students' achievement, interest and retention. In U. Nzewi (Ed), STAN procedures of the 47th Annual conference, 253-259.

Okigbo, E. C., \& Osuafor, A. M. (2008). Effect of using mathematics laboratory in teaching mathematics on the achievement of mathematics students. Educational Research and Review, 3(8), 257-261. Retrieved from http:/ / www.academicjournals.org/ERR

Pierce, R., \& Stacey, K. (2010). Mapping pedagogical opportunities provided by mathematics analysis software. International Journal of Computers for Mathematical Learning, 15(1), 1-20. https:/ / doi.org/10.1007/s10758-0109158-6

Saudi Arabia's Vision for 2030. (2017). Education. Retrieved from http:/ / vision2030.gov.sa/ar/node/188

Shalabi, N. M. (2014). A Proposed Framework for Integrating Skills of the 21st Century into Science Curriculum for the Basic Education in Egypt. International interdisciplinary Educational Journal, 3(10), 1-33.

Srinivasa, N. (1978). A Laboratory for teaching mathematics. JSTAN, 9(1), 22-24.

Stacey, K. (2005). The place of problem solving in contemporary mathematics curriculum documents. Journal of Mathematical Behaviour, 24(3-4), 341-350. https:/ / doi.org/10.1016/j.jmathb.2005.09.004

Suh, J., \& Moyer, P. S. (2007). Developing students' representational fluency using virtual and physical algebra balances. Journal of Computers in Mathematics and Science Teaching, 26(2), 155-173.

Ukeje, B.O. (2002). Production and retention of mathematical sciences teachers for Nigerian educational system. In S. O. Ale \& L. O. Adetula (Eds) (2005), Reflective and Intellectual Position papers on mathematics Education Issues, pp 80-102. Abuja; Marvelous Mike Nigeria Ltd.

Waits, B. K., \& Demana F. (2000). Calculators in mathematics teaching and learning: Past, present, and future. In M. J. Burke \& F. R. Curcio (Eds.), Learning mathematics for a new century (pp. 51-66). Reston, VA: National Council of Teachers of Mathematics.

Wheeler, D. (1967). Curriculum Process. London: University of London Press.

Yusuf, N., \& Atassi, H. (2016). Beyond Oil - The Transformation to a Market-Based Approach: Envision Saudi Arabia 2030. Journal of Economics and Sustainable Development, 7(14), 20-24.

\section{http://www.ejmste.com}

